\title{
Announcements of Going-Concern Problems Among Japanese Firms
}

\author{
Xavier Garza-Gomez \\ University of Houston-Victoria \\ Masashi Okumura \\ Waseda University \\ Ronald J. Salazar \\ University of Houston-Victoria
}

Using a sample of firms from the Japanese stock market, this paper tests models that predict (or explain) bankruptcy and return on assets to examine the information content of announcements of going-concern problems towards future performance. Overall results show that going-concern $(G C)$ announcements are helpful in predicting future performance and are robust to the inclusion of competing distress proxies. When the role of different types of going-concern announcements is explored, results show that information content varies among types of GC problems. In particular, announcements classified as "material loss", which are the least predictable among GC problems, have the strongest relation to future performance.

Keywords: going-concern problems, bankruptcy prediction, future performance.

\section{INTRODUCTION}

Announcements of going-concern (GC) problems in Japan differ from the process followed in the U.S. in that the firm, not the auditor, identifies the problem and discloses it in footnotes to its financial statements. The auditor then validates or confirms the problem and provides an explanation in the audit report. The information provided to investors is similar to auditor-initiated disclosures in the U.S. and in other countries following the International Financial Reporting Standard (IFRS). Prior to 2003, Japanese firms were not required to disclose GC issues. However, starting in 2003, firms have been required disclose GC issues in footnotes to financial statements. Using data relating to more than 1000 cases of GC issues reported between 2003 and 2009, this paper explores the effect of GC announcements (opinions) on profitability and bankruptcy.

Prior literature has documented that GC announcements convey important information for investors' decision making. One line of research focused on market reaction to the announcements, in which Dopuch et al. (1986) and Chen and Church (1996) report negative market reactions. Urayama (2006) analyzes Japanese stock market and reports negative abnormal returns around the opinion date. This stream of research produced some papers exploring the reaction to different types of auditor opinions. Among them, Holder-Webb and Wilkins (2000) test the difference between GC opinions based on SAS 59 and SAS 34 in the US while Bessell, Anandarajan, and Umar (2003) use a sample of Australian firms 
to explore the difference between 'Emphasis of Matter' and 'Except for' reports. Holder-Webb and Wilkins (2000) report differences in the reaction to the two classes of opinions while Bessell, Anandarajan, and Umar (2003) find no difference. Another line of research analyzes how the market valuation mechanisms change after GC announcements. Barth et al. (1998) and Blay et al. (2011) show that investors' attention to the income statement diminishes significantly after GC opinion release. Similarly, Choi and Jeter (1992) report a decrease in the earnings response coefficients as a consequence of audit reports.

This paper follows a different path. We posit that GC announcements are a clear signal that the firm is distressed. Disclosing a GC issue will signal impact on the firm's financial risk and performance, as reflected on the likelihood of declaring bankruptcy and on future earnings. That is, the actual disclosure (recognition) of the problem reflects stresses to the firm's business outlook (difficulty in obtaining credit, loss of costumers, etc.) that impact the future operations of the firm. Our paper tests the relationship between the reporting of GC problems and future performance. We use two models, probability of bankruptcy to measure risk, and future profitability (Return on Assets) to measure performance. Our analysis includes two sets of tests. First, we use a simple event study to measure risk and performance characteristics before and after the disclosure of the GC issue. Second, we use regression analysis applied to a sample of distressed firms in which observations of firms with and without GC problems are pooled in order to analyze the information content of different types of GC problems in the presence of common distress indicators. Our results on both sets of tests are strongly supportive of a relationship between GC announcements and future performance.

This paper makes several contributions to the literature. First, we build on previous literature and adapt popular models to test the information content of GC announcements. Our results strongly support the relationship between GC problems and several measures of future performance. Second, we explore the information content of different causes of GC announcements and classify GC cases into multiple categories to expose their impact. We identify important differences between GC problem types and frequencies. One such difference is that the GC problem type that is least expected by investors (material loss) has the strongest relation to future performance. Third, though previous studies have investigated distressed firms in the U.S., research on Japan in this area is quite limited. Therefore, we extend the literature by studying the types of GC problems in Japanese firms. The Japanese market has evolved significantly in the past decade and the number of firms has increased rapidly. We use a comprehensive database that contains all firms listed in Japan. Thus, our findings apply to all Japanese firms and equity markets for the period covered.

The paper is structured as follows: A discussion of relevant literature begins with a review of the relationship shown between GC modified opinions and returns close to the date of disclosure; then explains the importance of the Japanese context. The following section describes the main models (first bankruptcy and then profitability) tested in this paper. Next, we describe how GC problems are disclosed in the Japanese stock market and present descriptive statistics. The main results of the paper are presented in the penultimate section. Finally, we summarize our conclusions, contributions and suggest directions for future research.

\section{BACKGROUND AND MODEL DEVELOPMENT}

GC modified opinions result in negative market reactions in terms of returns (Dopuch et al.1986; Chen and Church 1996; Blay and Geiger 2001; Ittonen 2010; Menon and Williams 2010), particularly close to the publication date. Fleak and Wilson (1994) and Jones (1996) each raised the likelihood that a differential impact exists among different kinds of GC opinions since they have reported that only unexpected going concern opinions have a significant negative effect on stock prices. This is a question we wish to explore further with this work. Subramanyam and Wild (1996) and Barth et al. (1998) found that investors tend to estimate market value for distressed firms emphasizing book value having shifted away from using both book value and net income for other firms. This finding is supported by Blay et al. (2011) who showed that the shift in emphasis coincided with GC reports. 
The Japanese equity market is third in the world behind the US and China (World Bank, 2016), yet relatively few studies examine these issues within that context. Leading research in this area has traditionally concentrated on samples obtained from the US stock market and the number of empirical studies related to the information content of the disclosure of GC problem is quite limited for the Japanese market. We provide new evidence that cannot be anticipated from the results reported in earlier empirical studies and to minimize the biases that arise due to data snooping (see Lo and MacKinlay (1991)). In addition, Japan differs from the U.S. in culture, in institutional structures and in its regulatory framework. The reputation of US auditors and that of Japanese auditors is different as is their influence when issuing a going concern opinion so it is important to test the robustness of past US findings regarding going concern opinions as the patterns documented in the U.S. market may not be the norm.

Among the few studies applied to Japanese firms, Urayama (2006) reported negative returns around the opinion date, mirroring the research of the U.S. market. In a more recent study, Shirata and Sakagami (2008) explore differences between GC companies and non-GC companies analyzing qualitative information in financial reports. We extend empirically-based research in the Japanese context by testing the relationship between GC opinions and two financial variables (probability of bankruptcy and future profitability (ROA) on a very large sample of firms. The models to test these relations are explained in the next sections.

\section{Probability of Bankruptcy}

Bankruptcy is the ultimate business risk and the studies of its prediction began with Beaver's (1966) seminal paper, based on the information content of financial ratios. Read and Yezegel (2016) underscore the importance of GC opinions in predicting bankruptcy as do Cybinski, and Windsor (2005). On the other hand, a study by Lennox, (1999) using a UK sample reports that auditors' going concern opinions offer no additional incremental information about the probability of bankruptcy while Gerakos et al (2016) find that auditors do not efficiently use information when GC opinions are generated. With the use of a sample of Japanese firms, this study can shed some light into the different information value of GC opinions made by firms and auditors.

Two studies in the area on which we relied on are Ohlson (1980), which introduces the use of the logit model while and Zmijewski (1984), which discusses important methodological issues relating to sample selection for this type of study. This paper extends the bankruptcy prediction literature dealing with the role of GC opinions in predicting bankruptcies. Altman and McGough (1974) began this research stream by examining the effectiveness of auditors in issuing GC opinions in firms that ultimately file for bankruptcy. Their study suggests that GC opinions are an alternative explanatory construct for estimating firms' probability of bankruptcy.

Based on the work of Zmijewski and Ohlson the logit model we use to test the role of GC variables is:

Prob (bankruptcy $\left.{ }_{\mathrm{t}+1, \mathrm{t}+2}\right)=\mathrm{a}_{0}+\mathrm{a}_{1} \mathrm{ROA}_{\mathrm{t}}+\mathrm{a}_{2}(\mathrm{D} / \mathrm{A})_{\mathrm{t}}+\mathrm{a}_{3} \mathrm{WCap}_{\mathrm{S}} \mathrm{t}_{\mathrm{t}}+\mathrm{a}_{4} \operatorname{Ret}_{\mathrm{t}}+$ $\mathrm{a}_{\mathrm{n}}$ (other control variables $)_{\mathrm{n}, \mathrm{t}}+\mathrm{b}_{\mathrm{m}}$ (distress variables $)_{\mathrm{m}, \mathrm{t}}+\mathrm{c}_{\mathrm{s}}(\mathrm{GC} \text { variables })_{\mathrm{s}, \mathrm{t}}$

where we observe the probability of bankruptcy in the two years following the GC opinion. ROA is return on assets, $\mathrm{D} / \mathrm{A}$ is the Debt to Assets ratio and WCap/S denotes working capital deflated by sales. These three variables follow Ohlson and Zmijewski. The number of bankrupt firms during the sample period is 71, with 44 occurring in 2008. Our approach to modeling allows for the existence of control variables that are specific to the sample period or particular to Japanese companies or different sections of the Japanese stock market. This set of variables is explained in the next section with more detail and is added to all the models we test in this paper and when significant, are shown in our final test models. In addition to sample specific variables, a set of distress dummies based on income and equity is added to the model. We used four definitions for income: gross profit, operating income, ordinary income (which adds the recurring non-operating effect to operating income, i.e. interest expense) and net income. These dummy variables take the value of 1 on firms with negative equity $(\mathrm{N} \mathrm{Eq})$, negative gross profit (N Gr I), 
negative operating profit (N Op I), negative ordinary profit (N Or I) or negative net income (NNI). The role of the distress variables is to account for distress information available to the public. In this way, the GC variables (the set of variables being tested in this paper), if significant, will prove that their information content is useful beyond variables typically used to identify a distressed firm. The projected sign for both the distress variables and the GC variables is positive, as the presence of distress is expected to increase the probability of bankruptcy.

We expect that there is a positive association between the issuance of a GC opinion and the probability of a firm declaring bankruptcy in the following two-year period. We expect a positive relationship between the debt to asset ratio and the probability of a firm declaring bankruptcy in the following two-year period. We expect a negative association between return on assets and the probability of a firm declaring bankruptcy in the following two-year period. We expect a negative association between stock returns and the probability of a firm declaring bankruptcy in the following two-year period. Finally, we expect a positive association between leverage and the probability of a firm declaring bankruptcy in the following two-year period.

\section{Future Profitability}

The second construct we examine in this paper is future earnings. We model return on assets in the year following the GC opinion. Given that the objective of the paper is not to predict earnings, but to test the role of $\mathrm{GC}$ announcements in the presence of a robust explanatory model, we explore the contemporaneous effect of the variables included on earnings in order to determine the base model for our sample. As explained by Ou and Penman (1988) and others, the "transitory" components of earnings at time $\mathrm{t}$ are determined by changes in balance sheet and income statement items that occur during year $\mathrm{t}$. Another explanatory variable to explain next year's ROA is current ROA. This term attempts to capture the "permanent" component of earnings. The model that we constructed includes changes in sales and debt levels from year $t$ to $t+1$, as well as profit margin (PM) and size measured by total assets at time $t$. The resulting test model is thus:

ROA $_{\mathrm{t}+1}=\mathrm{a}_{0}+\mathrm{a}_{1} \mathrm{ROA}_{\mathrm{t}}+\mathrm{a}_{2} \Delta(\mathrm{D} / \mathrm{A})_{\mathrm{t}, \mathrm{t}+1}+\mathrm{a}_{3} \Delta(\text { Sales })_{\mathrm{t}, \mathrm{t}+1}+\mathrm{a}_{4} \mathrm{PM}_{\mathrm{t}}+\mathrm{a}_{5} \log (\text { Assets })_{\mathrm{t}}+$ $\mathrm{a}_{\mathrm{n}}(\text { other control variables })_{\mathrm{n}, \mathrm{t}}+\mathrm{b}_{\mathrm{m}}$ (distress variables $)_{\mathrm{m}, \mathrm{t}}+\mathrm{c}_{\mathrm{s}}(\mathrm{GC} \text { variables })_{\mathrm{s}, \mathrm{t}}$

The model is used for a sample of firms with negative net income. The projected sign for both the distress variables and the GC variables is negative, as the presence of distress is expected to signal decreased future earnings. Stock market dummies are used to control for heteroscedasticity. There is an expected positive association between the issuance of a GC opinion and negative net income and a similar association between the presence of distress variables and negative net income.

\section{DATA AND SAMPLE DESCRIPTION}

\section{Japanese Going-Concern Opinions}

Japanese public companies encountering certain situations have been required by law since 2003 to disclose them as footnotes to their financial statements. Such footnotes are included within the duty of the firm's auditors. Since GC opinion disclosure has been legally mandated, the information is widely available. Thus, the information is readily available to Japanese investors.

GC problems are classified by the Corporate Governance Evaluation System (CGES). Firms adding a disclosure typically classify the situation. GC opinions are classified in the following categories:

- GC1) Solvency: The forgiveness of debt, default on or difficulty of servicing loan, default on or difficulty in servicing bonds.

- GC2) Funding problem: Difficulty in obtaining additional funds.

- GC3) Decline in sales: Significant decline in sales.

- GC4) Serial loss: Net loss continued for several years. 
- GC5) Excess of Debts: Firm takes on excess debt.

- GC6) Material loss: Operating loss or net loss is material for the firm.

- GC7) Cause not specified

GC1 through GC5 are problems that can be observed by investors before the actual GC opinion. GC6, on the other hand, would typically be caused by a recent (unforeseen) event. Thus, we have classified GC1 to GC5 opinions to be "expected" and GC6 to be "unexpected". GC categories (or flags) are not mutually exclusive, occasionally firms simultaneously reveal several GC problems.

We used the CGES database to identify all reported GC opinions between 2003 and 2009. There were 3139 GC opinions relating to 508 firms. Table 1 shows the distribution of the GC opinions. These included firm-year observations containing several GC opinions. We identify 1970 cases in annual and interim reports and 1195 firm-year observations. We found 508 "new" cases. We observe a large increase in the number of cases in 2008, consistent with the global financial crisis of 2007. The most frequent were GC4 (serial loss) and GC6 (material loss) with more than 1000 cases each. Excess of debt (GC5) was the third most frequent problem identified. Of the 508 firms with GC opinions for the first time, 77 (fifteen percent) delisted within three months following the announcement.

TABLE 1

DESCRIPTION OF GOING-CONCERN ANNOUNCEMENTS IN JAPAN (2003-2009)

\begin{tabular}{|lcccccccc|}
\hline & 2003 & 2004 & 2005 & 2006 & 2007 & 2008 & 2009 & All years \\
GC Problems identified & & & & & & & & \\
GC1 - Solvency & 23 & 19 & 8 & 9 & 14 & 33 & 16 & 122 \\
GC2 - Funding problem & 9 & 6 & 7 & 8 & 10 & 50 & 12 & 102 \\
GC3 - Sharp decline of sales & 19 & 10 & 18 & 12 & 17 & 29 & 14 & 119 \\
GC4 - Serial Loss & 60 & 81 & 93 & 100 & 151 & 439 & 125 & 1049 \\
GC5 - Excess of Debt & 62 & 48 & 36 & 31 & 32 & 67 & 29 & 305 \\
GC6 - Material Loss & 91 & 90 & 98 & 104 & 159 & 544 & 173 & 1259 \\
GC7 - Not classified & 13 & 25 & 26 & 17 & 27 & 57 & 18 & 183 \\
Sum of GC problems & 277 & 279 & 286 & 281 & 410 & 1219 & 387 & 3139 \\
\# cases & 181 & 197 & 199 & 202 & 287 & 704 & 200 & 1970 \\
GC problems per GC case & 1.5 & 1.4 & 1.4 & 1.4 & 1.4 & 1.7 & 1.9 & 1.6 \\
\# firms with GC trouble & 129 & 130 & 131 & 128 & 181 & 297 & 199 & 1195 \\
GC Cases/firm-year & 1.4 & 1.5 & 1.5 & 1.6 & 1.6 & 2.4 & 1.0 & 1.6 \\
New unique cases & 92 & 53 & 41 & 47 & 82 & 120 & 73 & 508 \\
\# years / case & 1.4 & 2.5 & 3.2 & 2.7 & 2.2 & 2.5 & 2.7 & 2.4 \\
Firms that delisted after GC & 13 & 10 & 9 & 2 & 9 & 23 & 11 & 77 \\
Surviving firms & 79 & 43 & 32 & 45 & 73 & 97 & 62 & 431 \\
\hline
\end{tabular}

\section{Japanese Stock Market Peculiarities Addressed with Control Variables}

We attempt to reduce the risk of omitting salient variables that might account for cross sectional variation in risk and performance of Japanese companies, with classification dummy variables. Our first control variable addresses the different exchange(s) on which a given firm is listed. Companies in Japan 
can list in different stock exchanges simultaneously. The Tokyo Stock Exchange (TSE) is the largest Japanese exchange. The largest Japanese companies are generally listed on one or more of the most important exchanges. That is, the first tier of TSE, the first tier of the Osaka Stock Exchange (OSE) and the first tier of the Nagoya Stock Exchange (NSE). We have labeled this group of stocks (or exchange tier) Tier 1 stocks. These markets also have a second tier of stocks. The difference between the first and second tier is that listing requirements for the second section are less stringent. The number of firms listed in the second tier is larger. There are two regional markets (Sapporo SAE, and Fukuoka FUE) with similar listing requirements. Therefore, these five are combined to form Tier 2. Prior to 2000, there were 3 additional stock markets based in Hiroshima, Kyoto and Niigata but they merged with the Osaka stock exchange and the Tokyo stock exchange between 2000 and 2001. In addition to firms listed in electronic market JASDAQ, we have labeled a fourth tier, designed for venture firms "Emerging". Foreign firms are excluded from in this analysis and firms listed on several exchanges are only accounted in the largest.

Figure 1 shows the number of firms in each tier along with the total Japanese firms for the full decade of the 2000s. We observe that the number of Tier 1 firms is quite stable, at around 850. The number of Tier 2 firms exhibits the largest variation. Beginning with 1169 in 2000, tier 2 declined fifteen percent from its peak in September 2000. The number of Emerging companies on the other hand has shown a big increase from 195 firms in January 2000 to 591 firms by the end of the decade. Figure 2 illustrates the 10 -year pattern of the total market capitalization for each tier. The total cap of the market moved from 500 trillion yen in 2000 to a low of 250 trillion in Mar 2003 to reach a maximum of 600 trillion in Jun 2007. Tier 1 firms comprise the largest part of Japanese stock markets.

Firm characteristics differ among the more than 3,500 firms listed in Japanese stock exchanges. Table 2 illustrates values for several of these characteristics. The main difference across exchanges is the firm size or market cap. Tier 1 firms account for an average of 75 percent of the market capitalization of the Japanese market. Tier 2 is the second in importance with 13 percent; JASDAQ has 9 percent; and Emerging firms represent only about 2 percent. We introduce dummies for the market segments in an effort to control for size effect.

\section{FIGURE 1 \\ NUMBER OF FIRMS LISTED IN DIFFERENT MARKET SEGMENTS OF THE JAPANESE STOCK MARKET (2000-2009)}

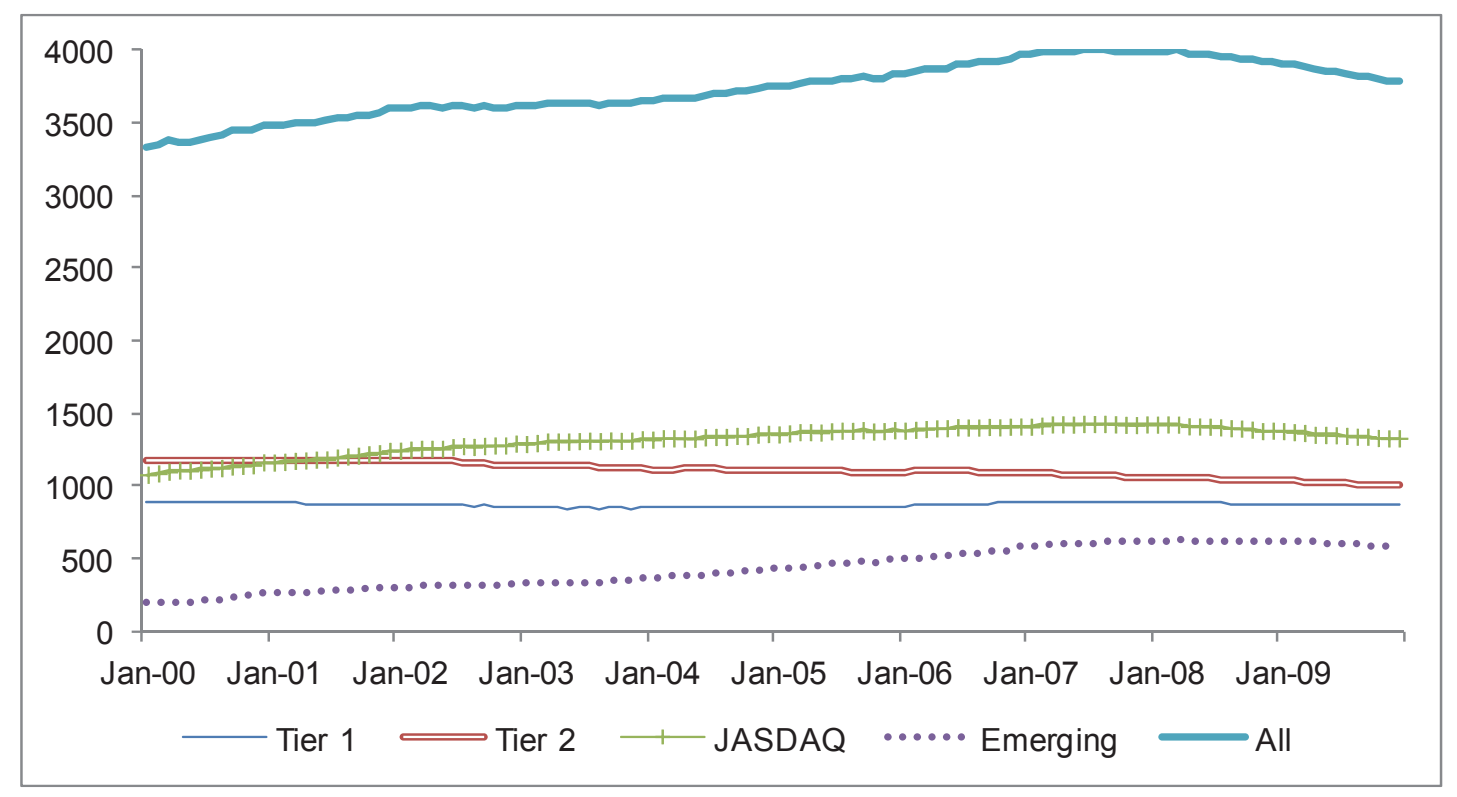


FIGURE 2

MARKET CAPITALIZATION (TRILLION YEN) OF ALL FIRMS IN THE JAPANESE STOCK MARKET (2000-2009), SEPARATED BY MARKET SEGMENT

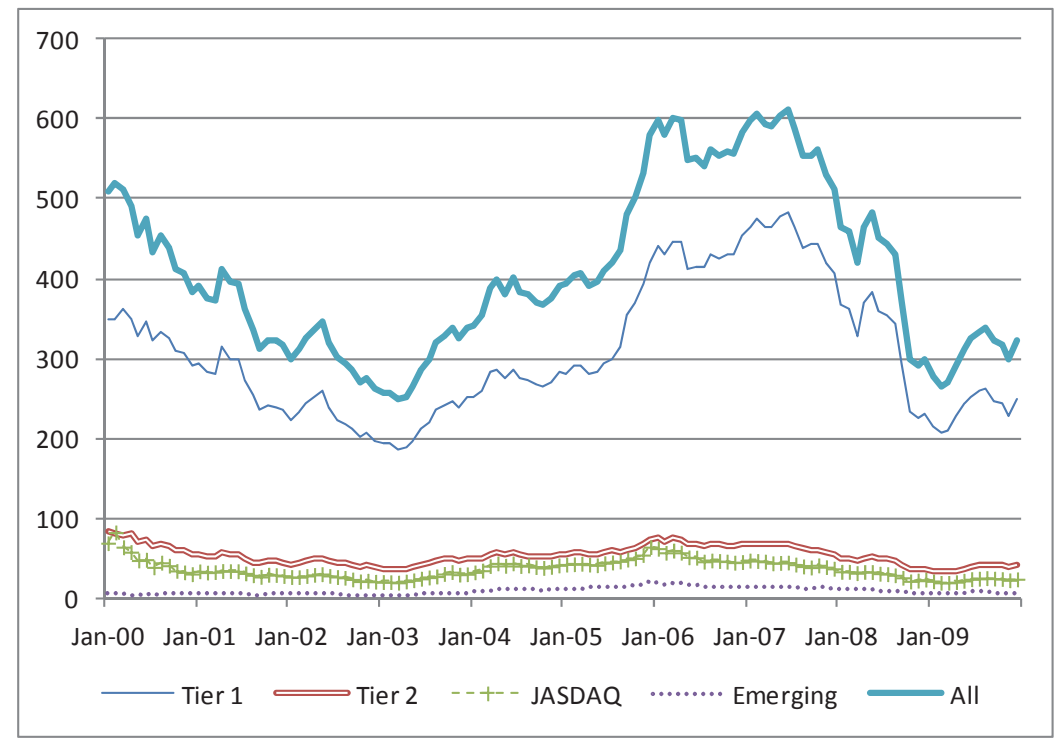

TABLE 2

CHARACTERISTICS OF FIRMS LISTED IN THE JAPANESE STOCK MARKET SEPARATED BY MARKET SEGMENT, (2000-2009)

\begin{tabular}{|lccccc|}
\hline & \multicolumn{5}{c|}{ Stock market segment } \\
& \multicolumn{5}{c|}{ All } \\
& Tier 1 & Tier 2 & JASDAQ Emerging & A \\
Capitalization/Valuation & & & & & \\
$\quad$ Average \# firms & 869 & 1108 & 1320 & 437 & 3734 \\
$\quad$ Average Market cap per firm (billion yen) & 354.8 & 48.9 & 28.3 & 22.1 & 110 \\
$\quad$ \% Japanese stock market & $75.4 \%$ & $13.2 \%$ & $9.1 \%$ & $2.3 \%$ & $100 \%$ \\
$\quad$ Assets (billion yen) & 709.1 & 93.4 & 47.8 & 40.9 & 228.8 \\
$\quad$ Book to market & 0.94 & 1.30 & 1.26 & 1.10 & 1.17 \\
Financial Ris k & & & & & \\
$\quad$ Number of bankrupt firms (10 years) & 51 & 48 & 36 & 3 & 138 \\
$\quad$ Debt/Assets & $60.6 \%$ & $53.9 \%$ & $51.8 \%$ & $47.9 \%$ & $54.2 \%$ \\
$\quad$ Fraction of firms with negative equity & $0.18 \%$ & $0.38 \%$ & $0.31 \%$ & $0.53 \%$ & $0.32 \%$ \\
Performance & & & & & \\
$\quad$ Return on Assets & $2.0 \%$ & $1.5 \%$ & $1.7 \%$ & $-1.0 \%$ & $1.4 \%$ \\
$\quad$ Profit margin & $2.3 \%$ & $1.4 \%$ & $1.0 \%$ & $-5.8 \%$ & $0.7 \%$ \\
& & & & & \\
\hline
\end{tabular}

\section{Characteristics of Firms Announcing GC Problems}

Table 3 shows selected financial and market characteristics of the firms with GC opinions. We observed that most failures following a GC opinion occurred among Tier 2 firms and stocks traded in JASDAQ. The failure rate among this group is above eighteen percent. By comparing the results to Table 2 we observe that GC firms exhibited lower market caps across all tiers. Their median stock price and 
book to market ratios were lower, as well. GC firms were also characterized by higher leverage, and a higher probability of negative equity. The percentage of firms with negative net income exceeded $80 \%$ for all market segments yielding negative averages for the population of GC firms. Profitability correlated directly with firm size. This occurs for each of the three measures of income used. This suggests a negative relation between size and risk. On the contrary, the proportion of firms with negative equity increases with size. We interpret this as evidence that investors' tolerance for negative equity is positively related to profitability.

TABLE 3

\section{SAMPLE CHARACTERISTICS OF FIRMS BEFORE THE FIRST ANNOUNCEMENT OF A GOING-CONCERN PROBLEM, SEPARATED BY MARKET SEGMENTS, (2003-2009)}

\begin{tabular}{|c|c|c|c|c|c|}
\hline \multirow{2}{*}{ Sample characteristics } & & & & & \\
\hline & Tier 1 & Tier 2 & JASDAQ & Emerging & Delisted \\
\hline Full sample & 49 & 117 & 206 & 136 & \\
\hline \# firms delisting & 6 & 23 & 38 & 10 & 77 \\
\hline Survival rate & $87.8 \%$ & $80.3 \%$ & $81.6 \%$ & $92.6 \%$ & - \\
\hline Average market capitalization (billion yen) & 60.4 & 9.5 & 3.9 & 5.2 & 3.5 \\
\hline Assets (billion yen) & 338.3 & 130.4 & 26.2 & 28.4 & 42.3 \\
\hline Book to market ratio & 0.12 & 0.30 & 0.36 & 0.21 & 0.46 \\
\hline Debt/Assets & $89.2 \%$ & $79.4 \%$ & $74.6 \%$ & $65.8 \%$ & $83.0 \%$ \\
\hline Profit margin & -14.3 & -33.2 & -27.4 & -86.5 & -30.5 \\
\hline Firms with negative equity $(\%)$ & $20.9 \%$ & $14.9 \%$ & $7.1 \%$ & $5.6 \%$ & $21.1 \%$ \\
\hline Firms with negative Operating income (\%) & $51.2 \%$ & $73.4 \%$ & $76.2 \%$ & $86.5 \%$ & $73.7 \%$ \\
\hline Firms with negative Ordinary income (\%) & $62.8 \%$ & $78.7 \%$ & $82.1 \%$ & $89.7 \%$ & $80.3 \%$ \\
\hline Firms with negative net income $(\%)$ & $83.7 \%$ & $89.4 \%$ & $91.7 \%$ & $94.4 \%$ & $90.8 \%$ \\
\hline
\end{tabular}

\section{METHODOLOGY AND RESULTS}

Our analysis is composed of two parts. First, we studied the sample of firms that survived the initial disclosure of any of the GC issue(s). We then compared the risk and performance before and after the announcement of the GC problem. Models (1) and (2) specified above are regressions testing the information content of the different GC categories.

\section{Risk and Performance Coinciding with the First Going Concern Announcement}

Table 4 shows the number of firms delisting soon after the GC announcement and the number that ultimately went bankrupt. In Japan, there are three acts that regulate the bankruptcy of business: Bankruptcy Act, Corporate Reorganization Act and Civil Rehabilitation Act. We recognize the bankruptcy cases when the firm files for the protection under any of these acts. We observe that delisting occurs mainly for smaller firms. Once the stock stops trading, the proportion of firms that go bankrupt is about $25 \%$. However, this proportion is much higher for large firms, where $67 \%$ of them end up in bankruptcy compared to only $10 \%$ of the emerging firms. This suggests that the possibility to continue as a private firm is much higher for smaller firms. 
The next panel presents return on assets before and following a GC opinion. Return on assets for surviving firms remains negative during the same period following the announcement of the first GC problem but Tier 1 firms show improvement. Overall evidence in this table suggests that the effect of a $\mathrm{GC}$ opinion for the first time is less damaging for Tier 1 (large) firms.

\section{TABLE 4 \\ CHANGE IN RISK AND PERFORMANCE SURROUNDING THE FIRST ANNOUNCEMENT OF A GOING-CONCERN PROBLEM (2003-2009) SAMPLE IS SEPARATED BY MARKET SEGMENT}

\begin{tabular}{|c|c|c|c|c|c|c|c|c|c|c|}
\hline & \multicolumn{2}{|c|}{ Tier 1} & \multicolumn{2}{|c|}{ Tier 2} & \multicolumn{2}{|c|}{ JASDAQ } & \multicolumn{2}{|c|}{ Emerging } & \multicolumn{2}{|c|}{ All } \\
\hline \multicolumn{11}{|c|}{ Corporate action after GC announce ment } \\
\hline Delisted & \multirow{2}{*}{\multicolumn{2}{|c|}{$\begin{array}{l}6 \\
4\end{array}$}} & \multicolumn{2}{|c|}{23} & \multicolumn{2}{|c|}{38} & \multicolumn{2}{|c|}{10} & \multicolumn{2}{|c|}{77} \\
\hline Bankrupt & & & \multicolumn{2}{|c|}{10} & \multicolumn{2}{|c|}{4} & 1 & L & \multicolumn{2}{|c|}{19} \\
\hline \multicolumn{11}{|c|}{ Performance after GC announce ment } \\
\hline \multirow[b]{2}{*}{$\mathrm{ROA}$} & Pre & Post & Pre & Post & Pre & Post & Pre & Post & Pre & Post \\
\hline & $-13.7 \%$ & $-1.4 \%$ & $-21.3 \%$ & $-18.6 \%$ & $-38.6 \%$ & $-36.7 \%$ & $-25.0 \%$ & $-23.3 \%$ & $-25.9 \%$ & $-22.5 \%$ \\
\hline
\end{tabular}

Sample size for surviving firms is 431 .

\section{GC Variables Used in the Models}

Next, we specify the combinations of GC categories used to examine the information content of GC opinions. GC1 to GC7 are the dummy variables that match the categories of GC opinion defined above. AnyGC is the dummy variable used to indicate the presence of a GC opinion for a firm $\mathrm{i}$ and time period $\mathrm{t}$ and is used in equations (1) through (5) to explain risk and performance at time $t+1$. We test the main hypothesis that firms with GC opinions exhibit an increase in investment risk and a deterioration of future performance with regressions (1) through (5) on a pool of distressed companies.

Robinson (2008) cautions that first-time going-concern opinions may be more difficult for auditors relative to modified opinions in subsequent periods, which suggests that the information contained in first GC or subsequent GC opinions is different. Because AnyGC, doesn't discriminate between single and multiple GC occurrences nor between first and subsequent occurrences our regression models are calculated including the following four sets of variables containing the same basic information

(a) AnyGC (the main GC variable)

(b) $1^{\text {st }}$ case and Ot case (separation of first and subsequent GC problem occurrences)

(c) MultGC and SingGC (separation of single and multiple occurrences)

(d) GC1, GC2, GC3, GC4, GC5, GC6, GC7 (specific type of GC problem)

Basic regression (a) will be the reference point used to assess if the additional level of detail of regressions (b), (c) and (d) is useful. Regression (b) ( $1^{\text {st }}$ case and Ot case) will be used to test whether the effect of the first disclosure of a GC problem is stronger or weaker than later GC occurrences. Regression (c) (MultGC and SingGC) can be used to test whether the effect of one single GC problem is lower than the effect of cases with several GC problems. Our expectation is that MultGC should have a stronger effect than SingGC. However, we can't make a prediction about the relative strength of the $1^{\text {st }}$ case and subsequent cases. If the first case shows a higher coefficient, we can conclude that the finding of a problem is more severe than its recurrence. However, since companies can get in and out of problems, the persistence of GC flags could also be an indicator of a more severe problem. Regression (d), which separates specific GC problems (GC1-GC7), allows us to assess which problem is more severe than the others. 
We stress that the information contained in Regressions (a) to (d) is exactly the same and that running these 4 regressions will produce similar results in terms of the goodness of fit (adjusted $\mathrm{R}^{2}$ ) but examining the relative importance of these competing variable definitions is an interesting empirical issue. These variables and their combinations are thus included in all the regressions presented in this paper.

\section{Probability of Bankruptcy}

The first panel in Table 5 presents the results for different versions of Model (1) examining the probability of future bankruptcy. We identify firms that declared bankruptcy in our sample in years $t+1$ and $\mathrm{t}+2$ to define our dependent variable. Then we apply a logit model to predict the probability of bankruptcy based on the models suggested in Zmijewski and Ohlson. Model 1A shows that the three variables introduced by Zmijewski are statistically significant. Model 1B introduces stock returns as an additional predictor and is significant. All signs are as described by Zmijewski and Ohlson with ROA and stock returns showing a negative relationship and leverage and working capital a positive one. When distress variables are added in Model $1 \mathrm{C}$, only the Negative ordinary profit dummy (N Or I) enters the equation but makes the coefficient of ROA insignificant. Nevertheless, the five variables are kept as the model to use to test the additional power of GC variables.

TABLE 5

\section{LOGIT REGRESSION RESULTS OF MODELS PREDICTING BANKRUPTCY IN THE NEXT 2 YEARS, SAMPLE OF DISTRESSED FIRMS (N=4630)}

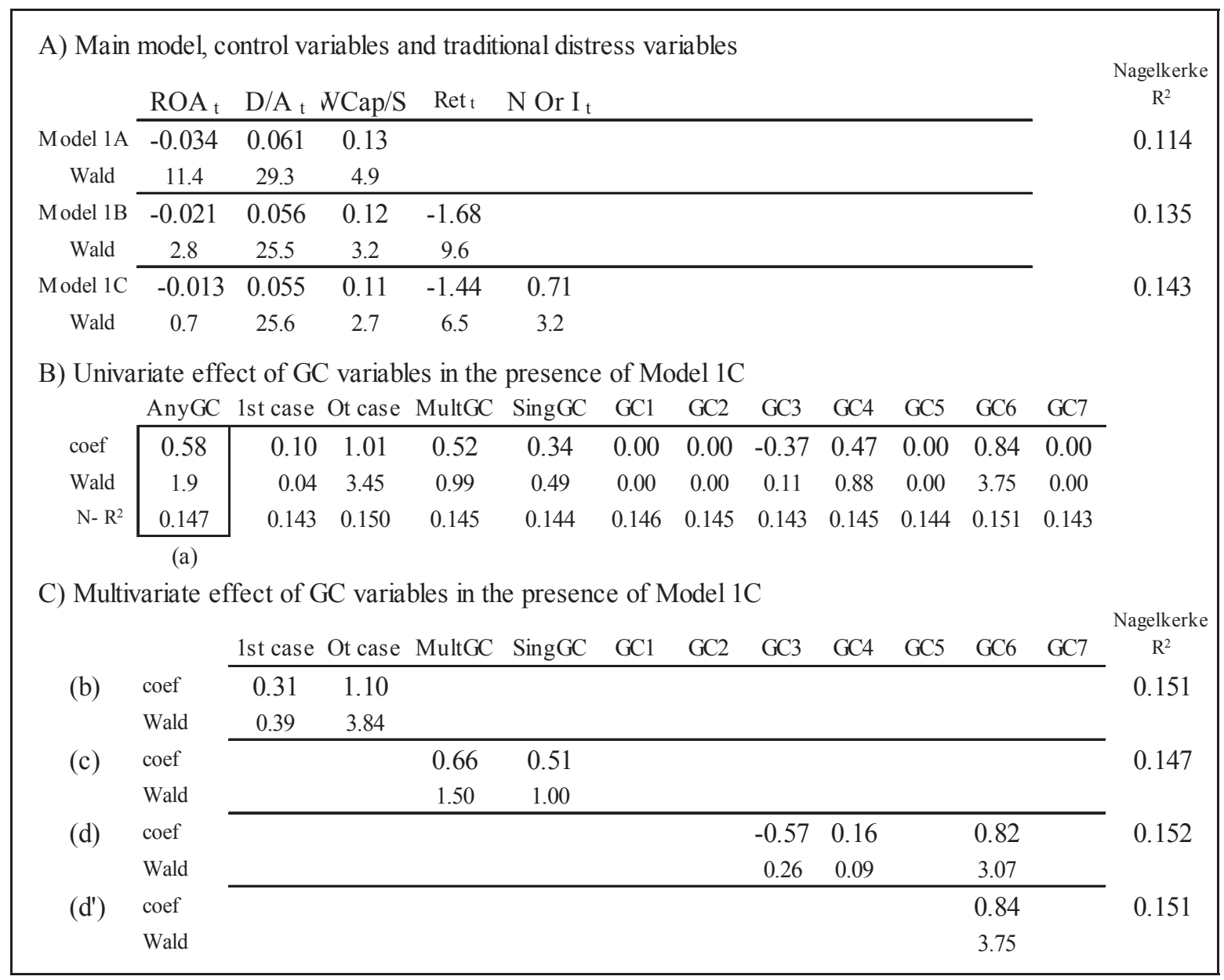


Distressed firms are identified as those with negative earnings or negative operating income. ROA, $\mathrm{D} / \mathrm{A}$, working capital and stock returns are measured at time $\mathrm{t}$. Bankruptcy filings occurring on year $\mathrm{t}+1$ and $\mathrm{t}+2$ are manually identified. GC dummies are obtained from the previous interim report.

Panel B shows the univariate effect of all GC dummies. The strongest of the GC dummies are GC6 and Ot case, both of them statistically significant. The sign is positive, as expected and the Nagelkerke $\mathrm{R}^{2}$ shows the largest increase. AnyGC also has a positive sign but the Wald statistic is only 1.9 (not significant at 10\%). When different combinations of GC dummies are tested in Panel C, results show that only Ot case and GC6 remain significant. This suggests that among companies with negative earnings, those companies with a GC opinion classified as material loss and companies disclosing GC problems for more than one year have a higher probability of going bankrupt than companies not reporting such conditions.

\section{Future Return on Assets}

Table 6 presents the results for different versions of Model (2) examining next year profitability, measured as return on assets. Model 2A is the simple autoregressive model for ROA and the $\mathrm{R}^{2}$ obtained is 0.118 . When contemporaneous variables are added in Model $2 \mathrm{~B}, \mathrm{R}^{2}$ increases significantly. Dummies for market tier and yearly dummies were tested and emerging markets dummy and yearly dummies for 2007 and 2008 were statistically significant. The negative sign for the yearly dummies confirms that the financial crisis that started in 2007 caused a severe shock among Japanese firms, especially for those with negative earnings. Model 2D shows that the coefficients of the negative gross income and negative ordinary income dummies were negative (as expected) and statistically significant. This model was used to test the explanatory power of GC variables. 
TABLE 6

\section{REGRESSION RESULTS OF MODELS WITH ROA AS DEPENDENT VARIABLE, SAMPLE OF FIRMS WITH NEGATIVE NET INCOME (N=2750 OBSERVATIONS)}

\begin{tabular}{|c|c|c|c|c|c|c|c|c|c|c|c|c|c|}
\hline \multicolumn{14}{|c|}{ A) Main model, control variables and traditional distress variables } \\
\hline & $\mathrm{ROA}_{t}$ & $\Delta \mathrm{Sal}_{\mathrm{t}+1}$ & $\Delta \operatorname{Lev}_{\mathrm{t}+1}$ & $\mathrm{PM}_{\mathrm{t}}$ & ln Assets t & Emerg $_{t}$ & Y2007 & Y2008 & $\mathrm{N}$ Gr It & \multicolumn{2}{|l|}{$\mathrm{N}$ Or $\mathrm{I}_{\mathrm{t}}$} & & \multirow{2}{*}{$\begin{array}{r}\text { Adj R } \\
0.118\end{array}$} \\
\hline \multirow{2}{*}{$\underset{t \text {-stat }}{\text { Model 2A }}$} & 0.42 & & & & & & & & & & & & \\
\hline & 19.2 & & & & & & & & & & & & \multirow{3}{*}{0.416} \\
\hline \multirow{2}{*}{$\begin{array}{c}\text { Model 2B } \\
\text { t-stat }\end{array}$} & 0.44 & 0.041 & -1.02 & 0.058 & 0.019 & & & & & & & & \\
\hline & 19.7 & 6.4 & -34.7 & 7.0 & 6.8 & & & & & & & & \\
\hline \multirow{2}{*}{$\begin{array}{c}\text { Model 2C } \\
\text { t-stat }\end{array}$} & 0.43 & 0.041 & -1.00 & 0.053 & 0.014 & -0.042 & -0.031 & -0.028 & & & & & \multirow[t]{2}{*}{0.422} \\
\hline & 19.4 & 6.4 & -33.8 & 6.5 & 5.0 & -3.69 & -2.81 & -2.70 & & & & & \\
\hline \multirow{2}{*}{$\begin{array}{c}\text { Model 2D } \\
\text { t-stat }\end{array}$} & 0.418 & 0.042 & -0.995 & 0.044 & 0.011 & -0.04 & -0.03 & -0.03 & -0.10 & -0.04 & & & \multirow[t]{2}{*}{0.429} \\
\hline & 18.71 & 6.64 & -33.81 & 5.33 & 3.96 & -3.45 & -2.52 & -2.6 & -3.9 & -4.3 & & & \\
\hline \multicolumn{14}{|c|}{ B) Univariate effect of GC variables in the presence of Model 2D } \\
\hline & AnyGC & 1st case & Ot case & MultGC & SingGC & GC1 & $\mathrm{GC} 2$ & GC3 & GC4 & GC5 & GC6 & GC7 & \\
\hline coef & -0.11 & -0.073 & -0.11 & -0.14 & -0.040 & -0.060 & -0.21 & -0.36 & -0.13 & -0.052 & -0.15 & -0.012 & \\
\hline t-stat & -8.9 & -4.0 & -7.2 & -9.0 & -2.2 & -1.68 & -4.69 & -9.6 & -8.3 & -2.16 & -10.5 & -0.35 & \\
\hline \multirow[t]{2}{*}{$\operatorname{Adj} R^{2}$} & 0.445 & 0.432 & 0.440 & 0.445 & 0.430 & 0.430 & 0.433 & 0.447 & 0.443 & 0.430 & 0.451 & 0.429 & \\
\hline & (a) & & & & & & & & & & & & \\
\hline \multicolumn{14}{|c|}{ C) Multivariate effect of GC variables in the presence of Model 2D } \\
\hline \multirow{3}{*}{ (b) } & & 1st case & Ot case & MultGC & SingGC & $\mathrm{GC} 1$ & $\mathrm{GC} 2$ & $\mathrm{GC} 3$ & GC4 & GC5 & GC6 & GC7 & \multirow{3}{*}{$\begin{array}{r}\operatorname{Adj~R}{ }^{2} \\
0.445\end{array}$} \\
\hline & coef & -0.094 & -0.12 & & & & & & & & & & \\
\hline & t-stat & -5.25 & -7.96 & & & & & & & & & & \\
\hline \multirow[t]{2}{*}{ (c) } & coef & & & -0.15 & -0.061 & & & & & & & & \multirow[t]{2}{*}{0.448} \\
\hline & t-stat & & & -9.40 & -3.41 & & & & & & & & \\
\hline \multirow[t]{2}{*}{ (d) } & coef & & & & & & -0.16 & -0.29 & -0.064 & 0.019 & -0.090 & & \multirow[t]{2}{*}{0.466} \\
\hline & t-stat & & & & & & -3.73 & -7.69 & -3.40 & 0.79 & -5.17 & & \\
\hline \multirow[t]{2}{*}{ (d') } & coef & & & & & & -0.16 & -0.29 & -0.07 & & -0.09 & & \multirow[t]{2}{*}{0.466} \\
\hline & t-stat & & & & & & -3.66 & -7.69 & -3.45 & & -5.13 & & \\
\hline
\end{tabular}

ROA, PM and other control variables are measured at time t. Increases of leverage and sales are measured between time $t$ and $t+1$

In Panel $\mathrm{B}$, the univariate effect of the $\mathrm{GC}$ variables is tested. All dummies show a negative coefficient suggesting that the disclosure of GC problem will decrease future profitability. With the exceptions of $\mathrm{GC} 1$ and $\mathrm{GC} 7$, all $\mathrm{GC}$ variables are statistically significant. When combinations of GC variables are tested (shown in Panel C), we find that subsequent GC cases appear to have a stronger effect than the first GC opinion. Similarly, multiple GC problems are associated with larger decreases in ROA than single GC opinions. When individual causes for GC problems are tested, four causes remain significant: GC2 (funding problem), GC3 (decline in sales), GC4 (serial loss) and GC6 (material loss).

\section{Robustness Test}

Sample selection is an important methodological issue. The tests performed explore the association of GC opinions to future performance of firms with negative earnings. We first tried to determine whether the announcements are informative among firms that are already distressed (negative earnings). As a robustness test, we repeated all the regressions in models (1) and (2) using an expanded sample that includes all Japanese firms (positive and negative earnings). The main change observed in the results (available upon request) is that more distress proxies (negative equity, negative earnings, negative gross profit, etc.) appear significant in the model used to test the GC disclosures. For example, the negative earnings dummy is significant in all regression models, which confirms the fact that firms with negative earnings are different from positive earnings firms. Regarding the information content of GC opinions, we report that more of the individual types of $\mathrm{GC}$ opinions are significant in multivariate models. For 
example, GC5, the excessive debt problem, which has a very high correlation with negative equity dummy, appears significant in the ROA return regressions. We report, however, that the main results remain the same: GC opinions have information content to explain future performance and GC6 (material loss) has the strongest role among the different types of GC problems.

\section{CONCLUSIONS}

This paper has explored the effect of GC announcements on the probability of bankruptcy and profitability of reporting firms. We report that in our sample period of 2003 to 2009, 15 percent of the firms that announce a GC problem delisted within three months of the first announcement. Preliminary analysis further showed that firms that survive the first announcement experienced significant increases in the likelihood of bankruptcy, and declines in their performance, measured by future return on assets. Regression results confirm that GC announcements are associated with increased probability of bankruptcy and decreased future return on assets. These results hold in the presence of common variables known to correlate with risk and performance.

Additional tests show that the type of GC problem that appears significant in all the models tested in the paper is GC6 (Material loss). We speculate that the reason that GC6 shows a consistent effect on all variables is the fact that material loss is less predictable than GC problems with other causes. For example, funding problems (GC1), declines in sales (GC3), serial losses (GC4) or excessive debt (GC5) do not appear suddenly. These problems arise over a longer period of time or as a consequence of numerous managerial decisions. On the other hand, material losses are normally linked to unexpected events (accidents, regulatory changes, legal issues, etc.), which would cause a stronger reaction from investors than chronic problems (as reflected by other GC classes). Our hypothesis that multiple GC problems would produce a stronger effect than single problems is supported for return on assets. The exploration of first cases vs. subsequent cases of GC problems suggests that subsequent cases have stronger explanatory power.

This paper builds on previous literature and adapts popular models to test the information content of GC announcements. Our results strongly support the relationship between GC problems and several measures of future performance. Second, we explore the information content of different causes of GC announcements and classify GC cases into multiple categories to expose their impact. We identify important differences between GC problem types and frequencies. One such difference is that the GC problem type that is least expected (material loss) by investors has the strongest relation to future performance. Third, though previous studies have investigated distressed firms in the U.S., research on Japan in this area is quite limited. Therefore, we further extend the literature by studying the types of GC problems in Japanese firms. The Japanese market has evolved significantly in the past decade and the number of firms has increased rapidly. We use a comprehensive database that contains all firms listed in Japan. Thus, our findings apply to all Japanese firms and equity markets for the period covered.

\section{REFERENCES}

Altman, E., \& McGough, T. (1974, December). Evaluation of a Company as a Going-Concern. Journal of Accountancy, 138(6), 50-57.

Barth, M. E., Beaver, W. H., \& Landsman, W. R. (1998). Relative valuation roles of equity book value and net income as a function of financial health. Journal of Accounting and Economics, 25(1), 134.

Beaver, W. E. (1966). Financial Ratios as Predictors of Failure. Journal of Accounting Research, 4, 71111

Bessell, M., Anandarajan, A., \& Umar, A. (2003). Information content, audit reports and going-concern: an Australian study. Accounting \& Finance, 43(3), 261-282.

Blay, A. D., \& Geiger, M. A. (2001, Summer). Market Expectations for First-Time Going-Concern Recipients. Journal of Accounting, Auditing and Finance, 209-226. 
Blay, A.D., Geiger, M.A., \& North, D.S. (2011). The Auditor's Going-Concern Opinion as a Communication of Risk. Auditing: A Journal of Practice \& Theory, 30(2), 77-102.

Chen, K. C. W., \& Church, B. K. (1996, January). Going-Concern Opinions and the Market's Reaction to Bankruptcy Filing. The Accounting Review, 71(1), 117-128.

Choi, S., \& Jeter, D. (1992). The Effects of Qualified Audit Opinions on Earnings Response Coefficients. Journal of Accounting and Economics, 15(2/3), 229-247.

Cybinski, P., \& Windsor, C. (2005). The Efficacy of Auditors' Going-Concern Opinions Compared with a Temporal and an Atemporal Bankruptcy Risk Model: Analysing U.S Trade and Service Industry Failures 1974 -- 1988. Pacific Accounting Review (Pacific Accounting Review Trust), 17(1), 3-36.

Dopuch, N., Holthausen, R. W., \& Leftwich, R. W. (1986). Abnormal Stock Returns Associated with Media Disclosures of 'Subject to' Qualified Audit Opinions. Journal of Accounting and Economics, 8(2), 93-117.

Fleak, S., \& Wilson, E. (1994, Winter). The Incremental Information Content of the Going Concern Audit Opinion. Journal of Accounting, Auditing and Finance, 9(1), 149-166.

Gerakos, J. J., Hahn, P., Richard, Kovrijnykh, A., \& Zhou, F. (2016). Prediction versus Inducement and the Informational Efficiency of Going Concern Opinions. Working Paper.

Holder-Webb, L. M., \& Wilkins, M. S. (2000, Spring). The Incremental Information Content of SAS No. 59 Going-Concern Opinions. Journal of Accounting Research, 38(1), 209-219.

Ittonen, K. (2010). Information Asymmetries and Investor Reactions to Going Concern Audit Reports. Working Paper, University of Vaasa.

Jones, F. L. (1996, Spring). The information content of the auditor's going concern evaluation. Journal of Accounting and Public Policy, 15(1), 1-27.

Lennox, C. S. (1999). The Accuracy and Incremental Information Content of Audit Reports in Predicting Bankruptcy. Journal of Business Finance \& Accounting, 26(5 \& 6), 757-778.

Menon, K., \& Williams, D. D. (2010, November). Investor Reaction to Going Concern Audit Reports. The Accounting Review, 85(6), 2075-2105.

Ohlson, J. (1980, Spring). A. Financial Ratios and the Probabilistic Prediction of Bankruptcy. Journal of Accounting Research, 18(1), 109-131.

Read, W. J., \& Yezegel, A. (2016). Auditor Tenure and Going Concern Opinions for Bankrupt Clients: Additional Evidence. Auditing: A Journal of Practice \& Theory, 35(1), 163-179.

Robinson, D. (2008). Auditor Independence and Auditor-Provided Tax Service: Evidence from GoingConcern Audit Opinions Prior to Bankruptcy Filings. Auditing: A Journal of Practice \& Theory, 27(2), 31-54.

Shirata, C. Y., \& Sakagami, M. (2008). An Analysis of the “Going Concern Assumption'? Text Mining from Japanese Financial Reports. Journal of Emerging Technologies in Accounting, 5, 1-16.

Subramanyam, K. R., \& Wild, J. J. (1996). Going Concern Status, Earnings Persistence, and Informativeness of Earnings. Contemporary Accounting Research, 13(1), 251-273.

Urayama, T. (2006). The Disclosure of Going Concern Problem and the stock reaction. The Kaikei, 169(3), 133-142 (in Japanese).

World Bank. (2016). Market capitalization of listed domestic companies (current US\$). Retrieved from http://databank.worldbank.org/data/reports.aspx?source=2\&type=metadata\&series=CM.MKT.LC AP.CD

Zmijewski, M. E. (1984). Methodological Issues Related to the Estimation of Financial Distress Prediction Models. Journal of Accounting Research, 22(Supplement), 59-82. 